\title{
Love Your Neighbor: The Community Health Plan in a Health Promoting Hospital in Taiwan
}

\author{
Wei-Hsin Huang ${ }^{1,2}$, Betty Chia-Chen Chang ${ }^{1}$, Shu-Chen Lee ${ }^{2}$, Li-Jen Liang², Nai-Fang Hu², \\ Yu-Hua Chen², Lee-Ching Hwang ${ }^{1,3}$
}

\section{About the AUTHORS}

${ }^{1}$ Department of Family Medicine, Mackay Memorial Hospital, Taipei, Taiwan ${ }^{2}$ Community Health Center, Mackay Memorial Hospital, Taipei, Taiwan

${ }^{3}$ Mackay Medical College, New Taipei City, Taiwan

Contact: Lee-Ching Hwang hlc@mmh.org.tw

\section{Introduction}

With the belief of "Healthy hospital, healthy community," the community health center at Mackay Memorial Hospital designed "The Community Health Plan." This team aided in setting up health service stations in the community, assessing health service needs, designing health promoting classes, holding preventive health care activities, and analyzing results for effectiveness evaluation. By being a "good partner of the community," Mackay Memorial Hospital was able to accomplish the goal of "making health a part of life and making life a part of health."

The hospital is situated in a metropolitan area; 46 health service stations have been set up in the nearby community based on community needs and characteristics. Health promoting topics included smoking cessation, chronic disease management, obesity prevention, workplace health promotion, healthy nutrition, physical activity promotion, and age-friendly care.

\section{The Community Health Plan}

The four community health projects and health-promoting activities held from 2014 to 2018 are described below.

\section{1. "Mackay Energy 2K" programs (1)}

The goal of the "Mackay Energy 2K" program was to encourage community residents to build healthy lifestyles, properly maintain self-health, and achieve effective body weight control.
There were four stages in this series of activities: 1st stage: "Mackay Energy $2 \mathrm{~K}$ plan" route selection, which involved planning fitness walking routes around the hospital that could be completed within 30 min or included 2000-2500 steps; 2nd stage: "Mackay Walking for Health," which encouraged staff members to join the activity by walking along the first-placed trail route; 3rd stage: "Everyone Walk Together," wherein families of staff members or community residents were invited to join the fitness walking activity, thereby scaling up the program; and 4th stage: "Healthy weight reduction," which promoted motivation for weight reduction through group competition.

\section{Weight management using lifesty-} le modification education model (2)

This goal of this project was to improve awareness of weight control and achieve body weight reduction or maintain healthy body weight through education on lifestyle modification. Educational sessions on diet and exercise were provided during fairs, classes, and health stations that had been set up in the communities. Body height, weight, and waist circumference were measured after joining this program. Phone interviews were conducted afterwards to track changes in the anthropometric measurements, understand one's consumption of vegetables and fruits and exercise routine, and provide counseling on healthy diet and exercise. 


\section{Research and Best Pratice}

3. A smoking cessation activity for taxi drivers in conjunction with the "Quit and Win" contest (3)

This project sought to analyze the effect on smoking cessation of taxi drivers belonging to the "Taiwan Taxi Company" through efforts by the Mackay smokingcessation team during the "Quit and Win" contest period. The smoking-cessation team comprised doctors, nurses, and pharmacists, who worked with the John Tung Foundation to provide counseling and medication to taxi drivers during the "Quit and Win" contest period.

\section{The health promotion services for community elderly (4)}

These services aimed to encourage the elderly to participate in community activities and increase health promotion behaviors. By collaborating with the elderly meal service program of Zhongshan District and Datong District, promoting health activities were delivered through consultation and lectures, including topics of prevention and management of common physiological or psychological problems in the elderly.
All the community health plans were well-received by the community. (1) "Mackay Energy $2 \mathrm{~K}$ " programs: there were 49 groups and up to 3,489 participants in this series of activities. This strategy promoted motivation to exercise in the community, and also helped participants pay more attention to their health. (2) Lifestyle modification education model: Over the period of 4 years, there were a total of 4,176 participants, achieving a total loss of $15,169 \mathrm{~kg}$. Most participants increased their vegetable intake and started to exercise regularly. (3) Smoking cessation activity: the point success rate at 3-month among taxi drivers was much higher than that of general smokers at the smoking cessation clinics (55.3\% vs $38.0 \%)$. This plan allowed taxi drivers to take the first step to quitting smoking. (4) Health promotion service: A total of 123 health promotion activities were conducted with 3,252 participants. Health instructions and referral information were given to participants with abnormal reports by healthcare staffs who also monitored their condition.

Table 1. Health-promoting activities (2014-2018) of The Community Health Plan in a health promoting hospital

\begin{tabular}{lcc}
\hline Activities & No. of activities & No. of people served \\
\hline Psychological health & 1,486 & 70,593 \\
Safe community & 293 & 20,002 \\
Volunteer training & 65 & 1,691 \\
Community epidemic prevention & 444 & 20,806 \\
Health literacy & 1,108 & 58,920 \\
Healthy diet & 910 & 17,616 \\
Health fitness & 256 & 11,831 \\
Tobacco hazards prevention & 142 & 8,169 \\
Cancer prevention & 400 & 18,965 \\
Elderly care & 1,917 & 20,286
\end{tabular}

\section{Conclusion}

A multidisciplinary team, comprising staff members from all departments in the hospital, worked together to successfully execute the "Community Health Plan." The support of the hospital and the trust of the community people are the keys to success. Mackay Memorial Hospital will continue to provide services wherever needed to promote comprehensive care for patients, families, and the community.

\section{Reference}

(1) Hwang LC, Chen YH, Lee SC, Hu NF, Chang CM, Chen CC. The effectiveness of "Mackay Energy 2K" programs. 23rd International HPH Conference on Health Promoting Hospitals and Health Service, oral presentation, 2015. (2) Hwang LC, Lee SC, Chuang JY, Chen YH, Liang LJ, Chang CM. The effectiveness of weight management using lifestyle modification education model: An experience of 4,000 participants. 24th International HPH Conference on Health Promoting Hospitals and Health Service, oral presentation, 2016.

(3) Huang WH, Chang Betty CC, Hwang LC, Chen YH. Effectiveness of a smoking cessation activity for taxi drivers in conjunction with the "Quit and Win" contest at a medical center in Northern Taiwan. 25th International HPH Conference on Health Promoting Hospitals and Health Service, poster, 2017.

(4) Lee SC, Tsai JM, Huang WH, et al. The experience of health promotion services for community elderly by a medical center. 26th International $\mathrm{HPH}$ Conference on Health Promoting Hospitals and Health Service, poster, 2018. 